STUDIEN UND TEXTE ZUR SOZIALGESCHICHTE DER LITERATUR

Herausgegeben von

Wolfgang Frühwald, Georg Jäger, Dieter Langewiesche, Alberto Martino, Rainer Wohlfeil

Band 17 

Harro Segeberg

\section{Literarische Technik-Bilder}

Studien zum Verhältnis von Technik- und

Literaturgeschichte im 19. und frühen 20. Jahrhundert

Max Niemeyer Verlag

Tübingen 1987

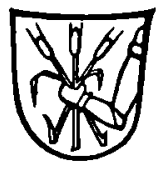


Als Habilitationsschrift auf Empfehlung des Fachbereiches Sprachwissenschaften der Universität Hamburg gedruckt mit Unterstützung der Deutschen Forschungsgemeinschaft

Redaktion des Bandes: Rainer Wohlfeil

CIP-Kurztitelaufnahme der Deutschen Bibliothek

\section{Segeberg, Harro:}

Literarische Technik-Bilder : Studien zum Verhältnis von Technik- u. Literaturgeschichte im 19. u. frühen 20. Jh. / Harro Segeberg. - Tübingen : Niemeyer, 1987.

(Studien und Texte zur Sozialgeschichte der Literatur ; Bd. 17)

NE: GT

ISBN 3-484-35017-2 ISSN 0174-4410

() Max Niemeyer Verlag Tübingen 1987

Alle Rechte vorbehalten. Ohne ausdrückliche Genehmigung des Verlages ist es nicht gestattet, dieses Buch oder Teile daraus auf photomechanischem Wege zu vervielfältigen. Printed in Germany.

Satz und Druck: Maisch + Queck, Gerlingen. Einband: Heinrich Koch, Tübingen 